\title{
Student Academy: A Pilot Design Thinking Workshop to Teach Community Medicine
}

\author{
Blake LESSELROTH ${ }^{\mathrm{a}, \mathrm{b}, 1}$, Hannah PARK ${ }^{\mathrm{c}}$, Helen MONKMAN ${ }^{\mathrm{b}}$, Shannon IJAMS a, \\ Ryan YARNALL ${ }^{\text {a }}$, Liz KOLLAJA ${ }^{\text {a }}$, J. Lee LUETKEMEYER ${ }^{\text {a }}$, and \\ Syeachia DENNIS a \\ ${ }^{a}$ University of Oklahoma School of Community Medicine, Tulsa, Oklahoma, USA \\ ${ }^{\mathrm{b}}$ School of Health Information Science, University of Victoria, Victoria, B.C., Canada \\ ${ }^{\mathrm{c}}$ School of Architecture and Design, University of Kansas, Lawrence, Kansas, USA
}

\begin{abstract}
The medical literature shows that social determinants of health have a significant impact upon health outcomes. However, health professionals often lack the skills to address these determinants at the systems-level. Therefore, we developed a Design Thinking workshop to teach about health-related social needs and to practice designing person-centered solutions. We piloted the workshop with 53 medical and physician assistant students; $69.8 \%$ responded to the post-workshop questionnaire. Nearly $80 \%$ of students agreed the workshop helped them understand the effect of context on clinical outcomes and demonstrated how to design patientcentered solutions. However, only $50 \%$ of respondents anticipated using the Design Thinking methods in their future practice. We need to identify more effective ways to demonstrate the practical application of Design Thinking to clinical work settings.
\end{abstract}

Keywords. Usability engineering, implementation science, health systems science, quality improvement, health literacy, social determinants of health, Design Thinking

\section{Background}

Literature suggests that social and structural determinants of health (SSDoH) have the greatest impact upon health outcomes [1,2]. To improve population health and bend the cost curve, healthcare organizations must identify SSDoH affecting vulnerable populations and work with stakeholders to improve person-centered models of care. Unfortunately, American healthcare organizations rarely engage patients in shared decision making or proactively address the ecological factors impacting health [3-5].

Educators, policy-makers, and administrators have argued that durable change requires clinicians to lead transformation efforts [6]. If clinicians are to adopt this expanded role of professionalism, training programs must integrate SSDoH and implementation science into their curricula. We believe the combined disciplines of informatics, design, and human factors offer innovative strategies to add this educational content.

Person-centered care begins with acquiring an understanding of patients and their lived experiences. However, there is often a large socioeconomic and cultural gap between providers and their patients. Health professionals may not recognize their own implicit biases and struggle to build empathy without a shared frame of reference [7].

\footnotetext{
${ }^{1}$ Corresponding Author: Blake Lesselroth, MD MBI; Email: Blake-Lesselroth@ouhsc.edu
} 
Health professionals also do not emerge from training programs with the skills to diagnose and improve sociotechnical systems [8,9]. They need tools to identify and understand the cultural features and perspectives meaningful to patients.

The classic two-pillared medical education model of basic and clinical sciences does not include pedagogical tools to teach health system science. Therefore, we piloted a workshop to teach medical and physicians assistant (PA) students about SSDoH. Our intent was to provide an immersive educational experience with the following learning objectives: (1) describe how SSDoH affect health outcomes; (2) explain how personcentered care can improve quality; and (3) use Design-Thinking (DT) to identify unmet patient needs and create person-centered solutions. In the next sections, we describe our methods, share pilot data, and offer advice for incorporating DT into curricula.

\section{Design Thinking and its Role in Health Care}

DT is a systematic problem finding and solving process that emphasizes user-empathy and person-centered design methods (Figure 1) [10]. DT has been widely used in the fields of design, engineering, and business [11]. We hypothesized that health professionals could use these methods to understand and address the needs of vulnerable patients. While designers and health professionals have been investigating the broad applications of DT in healthcare, little data exists on its use in medical education to address SSDoH.

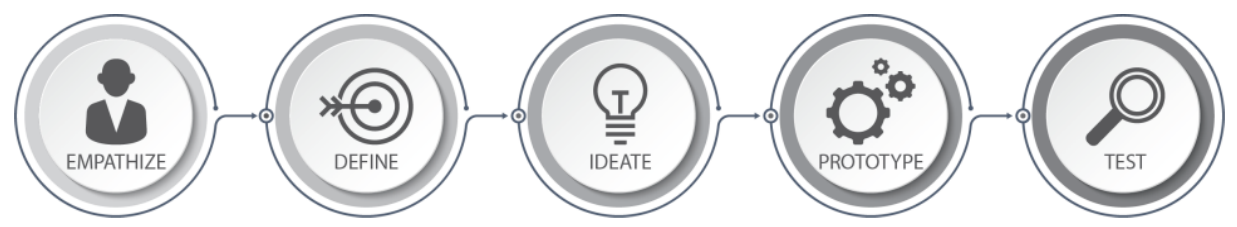

Figure 1. The Design Thinking framework adapted from Naiman ${ }^{11}$.

\section{Student Academy: Community Medicine Workshop}

A team of faculty from medicine, informatics, and design developed a virtual workshop targeting third-year medical and second-year PA students. The workshop included two parts: 1) a lecture and interactive activity on identity, privilege, and SSDoH; and 2) an introduction to DT methods for building empathy with patients, diagnosing user experience concerns, and engaging in person-centered problem-solving.

We used a mixture of teaching methods, including didactics, small group activities, and large group discussions (Table 1). Using a "flipped-classroom" approach, we distributed pre-session reading materials to students and focused our didactics on topics critical to reinforce learning objectives and set the stage for interactive work. A faculty member (SD) with public health expertise gave a keynote lecture describing SSDoH and the impact of structural racism and poverty on health. Our informatics and design faculty (BL, HP) gave a lecture on DT using real-life examples both in and outside of healthcare.

We gave students a hypothetical scenario: a 45-year-old Latina woman with diabetes and hypertension attending her first telemedicine appointment. We challenged students to creatively approach how they would provide a post-visit summary with laboratory 
values, medications, and a care plan. Students worked in groups of five members to create three DT products: (1) a patient persona (i.e., archetype of a group with similar needs and behaviors); (2) a patient journey map (i.e., visualization of a user interacting with a system over time); and (3) a wish list (i.e., list of needs statements that describe the user, the need, and underlying goal) [12]. For each activity, we adapted instructions compiled by Banfield, Lombardo, and Wax [13].

Table 1. Agenda for the Student Academy Design Thinking Workshop (total time approximately 5 hours).

\begin{tabular}{cll}
\hline $\begin{array}{c}\text { Duration } \\
(\mathbf{m i n})\end{array}$ & \multicolumn{1}{c}{ Activity } & \multicolumn{1}{c}{ Description } \\
\hline 60 & $\begin{array}{l}\text { Small group activity: } \\
\text { Privilege \& identity }\end{array}$ & $\begin{array}{l}\text { Faculty guided learners through a simulation using limited } \\
\text { funds to "purchase" existential societal privileges such as } \\
\text { access to care or personal safety. }\end{array}$ \\
& $\begin{array}{l}\text { Lecture: Health as a } \\
\text { function of Geography and } \\
\text { Racialized Identity } \\
\text { disparities concentrated in communities of color and how }\end{array}$ \\
& $\begin{array}{l}\text { Introduction to systems- } \\
\text { thinking using person- }\end{array}$ & $\begin{array}{l}\text { Faculty introduced person-centered design and a } \\
\text { hypothetical design challenge affecting a patient presenting } \\
\text { to a telemedicine clinic for the first time }\end{array}$ \\
& $\begin{array}{l}\text { centered design } \\
\text { Lecture: DT to improve } \\
\text { healthcare quality }\end{array}$ & $\begin{array}{l}\text { An overview of the goals, methods, and outputs of DT; } \\
\text { presentation of example deliverables }\end{array}$ \\
& $\begin{array}{l}\text { Small group activity: } \\
\text { Persona development }\end{array}$ & $\begin{array}{l}\text { Faculty guided learners to create a patient persona for a } \\
\text { Latina female with diabetes and hypertension }\end{array}$ \\
& $\begin{array}{l}\text { Small group activity: } \\
\text { Creating a journey map }\end{array}$ & $\begin{array}{l}\text { Faculty guided learners to fill out a journey map describing a } \\
\text { telemedicine visit }\end{array}$ \\
& $\begin{array}{l}\text { Small group activity: Wish } \\
\text { list of design requirements }\end{array}$ & $\begin{array}{l}\text { Faculty guided learners using the wish list method to draft } \\
\text { requirements for a post-visit clinical summary }\end{array}$ \\
\hline
\end{tabular}

DT: Design Thinking

\section{Evaluation Method}

We distributed a post-workshop survey that included questions with Likert-type scales and open-ended questions. The scaled items asked participants to (1) indicate how well the workshop met learning objectives; (2) if the teaching methods were effective; and (3) if they would use DT in practice. The open-ended questions asked participants to list workshop strengths and weaknesses. Medical and PA students took the same survey.

\section{Findings}

Fifty-three students participated in the workshop and $37(69.8 \%)$ completed some or all of the survey (Figure 2). Nearly $85 \%$ of responses indicated the SSDoH lecture met the learning objectives. Eighty percent of respondents said the workshop helped understand the effect of context on patient outcomes and $80 \%$ said the workshop provided ways to design patient-centered solutions. Most learners (78.6\%) said the workshop helped them reflect upon their own practice. However, many did not think persona development was a valuable activity and believed creating a hypothetical persona without gathering ethnographic data could perpetuate bias. Respondents proposed practical solutions to reduce bias such as providing specific patient details, distributing real-life cases, or 
incorporating standardized patients interviews in the workshop. One learner wrote, "most of us...come from rather privileged backgrounds and sometimes may not even be able to truly understand...the needs and lived experiences of the highly underserved populations of patients we work with every day. '

Approximately, $50 \%$ of respondents anticipated using the DT methods from this session in their future practice. One student wrote,

"I do believe this topic is important, but I am not sure it is actually something I would do while taking care of my patients."
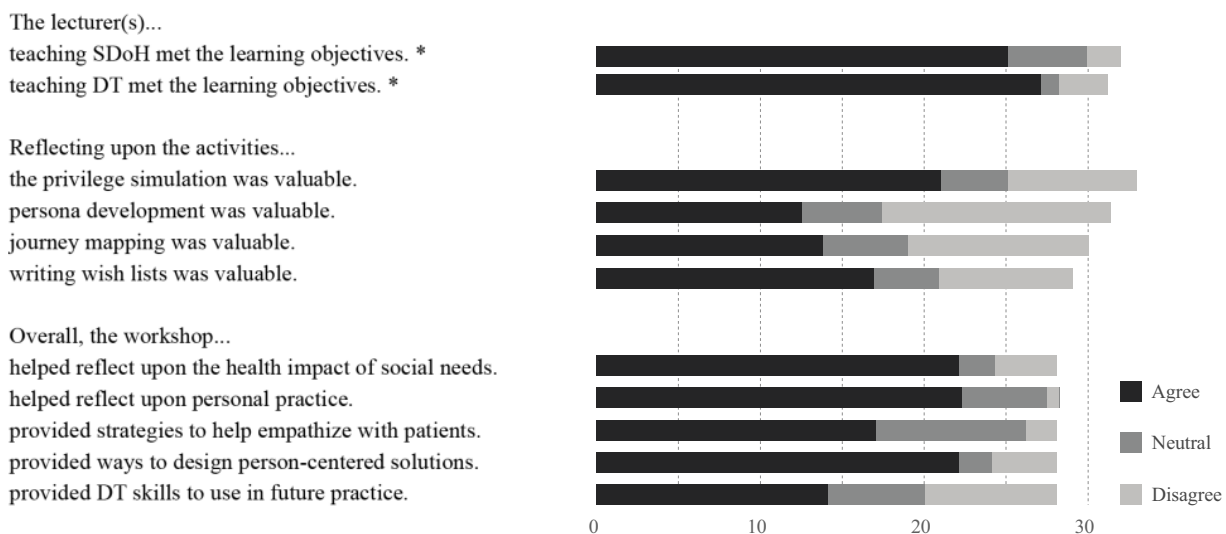

* DT: Design Thinking SDoH: Social determinants of health Numbers of participants

Figure 2. Summary of quantitative findings from the learner satisfaction survey $(\mathrm{N}=37)$.

\section{Discussion}

Principle findings. Our workshop offers a dynamic approach for teaching about SSDoH and illustrating how to design systems-level solutions. The lectures and large group activities fostered dialogue around health-related social needs and the evolving roles for health professionals. The small group activities gave learners hands-on practice using visual design tools and applying systems engineering methods. Most students found the content valuable and agreed it provided insights on how they can design new systems. However, $50 \%$ of respondents did not see themselves using DT in their own practice. These theoretical concepts may be difficult to synthesize when learners are still learning foundational patient care concepts. Also, students may not be able to visualize the practical applications until having worked on real quality improvement projects.

Implications and future directions for DT in curriculum. The DT framework and methods are teachable concepts that faculty can use to introduce health-systems thinking, integrate multiple educational program objectives, and assess entrustable professional activities. It also complements other quality improvement paradigms (e.g., Plan-DoStudy-Act model) by operationalizing ways to incorporate person-centered design into planning and implementation phases. Finally, the virtual platform and interactive visual collaboration software enabled faculty experts around the globe to participate.

In the future, we need to illustrate the connection between these lessons, students' future roles, and future behaviors. To make this curriculum more impactful, we need to find more opportunities to demonstrate the practical applications of DT in healthcare. 
For example, we may link these lessons to other quality improvement projects. We also need to integrate ethnographic and "real-world" data to ground the instruction. Our workshop could include interactions with standardized patients, recorded interviews with real patients, or locally collected public health and community demographic data [14].

\section{Conclusions and Limitations}

We believe DT helps keep users at the center of the design process and promotes ideation to reach breakthrough innovations. This is critical when teaching health professionals about person-centered and context-sensitive care. However, there are limitations to this work. First, this was a pilot at one school; we need to test with more learners in other health professional roles. Second, the low participant response rate may have introduced a systematic bias (e.g., those less satisfied with the workshop were more likely to respond). Finally, it is important to objectively measure learning and behavior over time. For example, in future work, we should include pre/post attitude surveys, grade deliverables, and measure professional attitudes and behaviors among our graduates.

\section{References}

[1] McGovern L, Miller G, Hughes-Cromwick P. The relative contribution of multiple determinants to health. Health Affairs Health Policy Brief 2014;10.

[2] Murray TA. Teaching the Social and Structural Determinants of Health: Considerations for Faculty. SLACK Incorporated Thorofare, NJ; 2021.

[3] McCarthy DM, Waite KR, Curtis LM, Engel KG, Baker DW, Wolf MS. What did the doctor say? Health literacy and recall of medical instructions. Medical care 2012;50:277.

[4] Koh HK, Brach C, Harris LM, Parchman ML. A proposed 'health literate care model'would constitute a systems approach to improving patients' engagement in care. Health affairs 2013;32:357-67.

[5] Mullangi S, Ibrahim AM, Chopra V. Toward Patient-Centered Hospital Design: What Can Airports Teach Us? : American College of Physicians; 2017.

[6] Skochelak SE. Health systems science e-book: Elsevier Health Sciences; 2020.

[7] Coulehan JL, Platt FW, Egener B, et al. "Let me see if I have this right...": words that help build empathy. American College of Physicians; 2001.

[8] Huang WY, Malinow A. Curriculum and evaluation results of a third-year medical student longitudinal pathway on underserved care. Teaching and learning in medicine 2010;22:123-30.

[9] Freeman J, Ferrer RL, Greiner KA. Developing a physician workforce for America's disadvantaged. Academic Medicine 2007;82:133-8.

[10] Park H, Monkman H, Wenger A, Lesselroth B. Portrait of Ms. Diaz: Empirical study of patient journey mapping instruction for medical professional students. Knowledge Management \& E-Learning: An International Journal 2020;12:469-87.

[11] Naiman L. Design thinking as a strategy for innovation. The European Business Review, June, https://www europeanbusinessreview com/designthinking-as-a-strategy-for-innovation 2019.

[12] Test your prototypes: How to gather feedback and maximize learning. Interaction Design Foundation, 2020. (Accessed July 8, 2021, at https://www.interaction-design.org/literature/article/test-yourprototypes-how-to-gather-feedback-and-maximise-learning.)

[13] Banfield R, Lombardo CT, Wax T. Design sprint: A practical guidebook for building great digital products: "O'Reilly Media, Inc."; 2015.

[14] Lesselroth B, Monkman H. Narratives and Stories: Novel Approaches to Improving Patient-Facing Information Resources and Patient Engagement. Context Sensitive Health Informatics: Sustainability in Dynamic Ecosystems: IOS Press; 2019:175-80. 